\title{
Correction to: Determinants of Intra-Region and Extra-Region Foreign Direct Investment Inflow in ASEAN: A Spatial Econometric Analysis
}

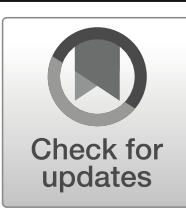

\author{
Hong Hiep Hoang ${ }^{1}$ (D) Michaël Goujon ${ }^{2}$
}

Published online: 19 July 2019

(C) Springer Nature B.V. 2019

\section{Correction to: Applied Spatial Analysis and Policy https://doi.org/10.1007/s12061-018-9280-8}

The original version of this article unfortunately contains incorrect statement in the Acknowledgments section.

The correct statement should be.

Acknowledgments This research is funded by Vietnam National Foundation for Science and Technology Development (NAFOSTED) under grant number 502.01-2019.25.

Pulisher's Note Springer Nature remains neutral with regard to jurisdictional claims in published maps and institutional affiliations

The online version of the original article can be found at https://doi.org/10.1007/s12061-018-9280-8

Hong Hiep Hoang

Hoanghonghiep@gmail.com; hiephh.isscr@vass.gov.vn

Michaël Goujon

michael.goujon@udamail.fr

1 Institute of Social Sciences of the Central Region (ISSCR), Vietnam Academy of Social Sciences, Nam Ky Khoi Nghia Street, Ngu Hanh Son District, Da Nang City, Vietnam

2 Centre d'Etudes et de Recherches sur le Développement International (CERDI), University of Auvergne, CNRS, 65 boulevard François Mitterrand, 63000 Clermont-Ferrand, France 